\title{
La Politica del Historicismo en el Discurso Jurídico Multicultural: la Jurisprudencia Constitucional sobre la Identidad de los Pueblos Indígenas y la Idea de Nación en Colombia
}

\author{
A Politics of Historicism in the Discourse of Multiculturalism Law: the \\ Constitutional Jurisprudence about Indigenous People Identity and the \\ Concept of Nation in Colombia
}

\author{
Oscar Andrés López Cortés ${ }^{1}$ \\ Tulio Enrique Rojas Curieux ${ }^{2}$ \\ ${ }^{1}$ Universidad Libre, Bogotá, Colombia \\ ${ }^{2}$ Unviersidad del Cauca, Bogotá, Colombia
}

\begin{abstract}
Resumen: En este artículo argumentaré que una política del historicismo determina el discurso jurídico y de esa manera, construye un relato lineal del tiempo en que los eventos se suceden de forma cronológica con el fin de ordenar la vida de las personas afectadas por ese discurso. Para mostrar la manera como dicho proceso tiene lugar, se expone la tensión suscitada entre la idea de nación presente en la Constitución Política colombiana de 1991 y la noción de identidad que promueve el multiculturalismo jurídico, mediante un estudio de algunas de las sentencias más relevantes en este aspecto, proferidas por la Corte Constitucional colombiana.
\end{abstract}

Palabras clave: Historicismo. Identidad. Law.

Abstract: A politics of historicism determines legal discourse to build a linear narrative of the time in which events happen. This fact produces a chronological view that influences the life of affected people who are under this discourse. Therefore, this article explains how this process takes place in order to evidence the tension between the concept of nation that is embodied in the Political Constitution of Colombia (1991) and, the notion of indigenous people identity that is promoted by multicultural laws. The analysis is based on the most relevant jurisprudential pieces of the Constitutional Court of Colombia towards the problem.

Keywords: Historicism. Identity. Multiculturalism.

Recebido em: 24/09/2019

Revisado em: 16/03/2020

Aprovado em: 29/04/2020

Direito autoral e licença de uso: Este artigo está licenciado sob uma Licença Creative Commons.Com essa licença você pode compartilhar, adaptar, para qualquer fim, desde que atribua a autoria da obra, forneça um link para a licença, e indicar se foram feitas alterações. 


\section{Introducción}

A quienes son formados en el derecho, se les enseña desde temprano que la disciplina jurídica viene de Roma. De hecho, una cátedra central en la formación de los abogados es "Derecho Romano"; ya muchos se han ocupado de debatir lo arbitrario que resulta la centralidad dada en la disciplina a esa asignatura (MONATERI, 2006). Por si aún nos quedan dudas, el trabajo de Martín Bernal (1993) como también el de Enrique Dussel (2007), han mostrado la manera como el derecho romano en realidad era norafricano. Muchas de las instituciones jurídicas plasmadas en el Código Civil de Napoleón se desarrollaron en lo que hoy conocemos como Siria y Turquía, mucho antes de llegar a Roma.

¿Por qué se insiste entonces en la enseñanza del derecho romano? ¿Por qué no cambiar el nombre de esta asignatura y denominarla el derecho norafricano que llegó a Roma? Se trata de un relato histórico que vincula a la Europa republicana del Siglo XVIII con las culturas latina y helénica, y por esa vía, se le adjudica a la Francia republicana el título de heredera legítima del legado romano. Pero esa sería solo una consecuencia de la manera en que opera el historicismo en el derecho. Lo que se argumentará en este artículo, es la manera como el historicismo se manifiesta en el discurso jurídico, y aún más, cómo el historicismo determina esa formación discursiva particular conocida como derecho. Luego de ello, a través de la tensión suscitada entre la idea de nación presente en la Constitución Política del 91 y la noción de identidad que promueve el multiculturalismo jurídico, será expuesta la manera como el proceso teórico descrito en la primera parte, tiene lugar en la práctica. Finalmente serán presentadas las conclusiones.

\section{La Presencia del Discurso Historicista en el Derecho}

La historiografía del derecho hace parte de un relato de origen que construyeron las disciplinas europeas a partir de los siglos XVII y XVIII, reivindicando la sociedad del antiguo mundo grecolatino: la historia del 
derecho romano, que luego es impuesta a buena parte de los estados nación de Europa occidental.

Con Trouillot (2011), se puede afirmar que se trata de otra forma de consolidar la centralidad del Atlántico norte. Allí está el centro de la geografía jurídica imaginada pero también el sitio desde el cual es contada esa historia. Durante los siglos posteriores a la construcción del estado nación, la lógica jurídica eurocéntrica se impondrá con menor o mayor éxito a la mayoría de los pueblos colonizados del mundo, movimiento mediante el cual se demarca un origen común impuesto por los múltiples procesos de colonización.

Esta colonización fue posible gracias, entre otras, a que la monarquía francesa constituyó el "ministerio de la historia", que tomó forma en 1781 bajo la denominación de Biblioteca de legislación, de administración, historia y derecho público (Foucault, 2000), la cual reunió los materiales documentales relacionados con las finanzas del reino y el archivo epistolar creado en 1763 disponible para los interesados en la historia y en el derecho público francés. Este material, reservado a los ministros reales y a aquellos que eran pagados por la Corte, fue fundamental en la construcción del derecho constitucional, del cual países como Colombia aun conservan importantes herencias teóricas, institucionales y normativas, tal y como muestran los trabajos de García (et. al. 2013), Naranjo (2010), De Gaudussond (2009), Aguilera (1965), entre otros.

Como sucedió en la mayoría de las excolonias ibéricas en el Siglo XIX, durante la formación de la república el derecho colombiano se consolidó a partir del derecho francés, del ius gentium o derecho de gentes. Sus vestigios surgen por todas partes: las instituciones del derecho civil colombiano, como ha mostrado Mantilla (2005); las instituciones del derecho administrativo y la figura de los consejeros de estado, como exponen Malagón y Gaitán (2008); el papel de Francia en el proceso en las guerras contra España y la formación del derecho, como lo demostró Ortíz (1960); la importancia de la figura presidencial, como señala García et al. (2013), son algunos ejemplos que muestran el legado galo en América. 
No es extraño que algunos de los fundamentos axiológicos del derecho constitucional en Colombia se deben a la interpretación francesa de aquel material documental que reunía piezas de toda la edad media e incluso del periodo anterior, material sobre el cual, anota Foucault (2000), trabajaron intensamente los historiadores del siglo XIX: Agustín Thierry y Guizot, y por esa vía, los juristas del mismo periodo.

Ahora bien, Foucault (2007) considera que un principio destacable de limitación de la razón de Estado durante la edad media fue el derecho, pues a través de este el poder real restringió progresivamente la capacidad de maniobra del poder feudal. No obstante, esto dio un giro a partir del siglo XVII y XVIII cuando el derecho se constituyó en un enclave para quienes buscaron limitar la extensión indefinida de la razón de Estado durante el desarrollo de lo que Foucault denominó la ampliación de la nueva racionalidad gubernamental. A partir del siglo XVII y el XVIII el derecho actuará como un sustractor del poder real, y no un multiplicador de este.

Sin embargo, según Foucault (2007), la pregunta no sería cómo extender a todos los ámbitos de la vida el gobierno del poder, por el contrario, la cuestión sería definida en estos términos: cómo no gobernar demasiado; sobre esa respuesta estaría basada la crítica interna de la razón gubernamental moderna, por oposición a la forma anterior de limitación del poder gubernamental constituido por el derecho como limitante externo. Aproximadamente a partir del siglo XVIII, el instrumento intelectual que permitirá a la razón gubernamental autolimitarse, será la economía política, y no el derecho. La economía política, contrario a lo ocurrido con el derecho durante los siglos XVI y XVII, se desarrolló como parte de la razón de Estado; la causa: el objetivo de la economía política es precisamente el enriquecimiento del Estado, entendido como el "crecimiento simultáneo, correlativo y conveniente ajustado de la población por un lado y de los artículos de subsistencia por otro.” (FOUCAULT, 2007, p. 31)

En contra del planteamiento de Foucault, los juristas siguen confiando en el derecho como límite de la razón gubernamental en el ejercicio del poder. Los defensores del multiculturalismo jurídico no constituyen la excepción; aun con sus matices, mantienen firme la idea 
de que es el derecho, y no la economía política, el mecanismo a través del cual se recortan los límites del poder de las mayorías nacionales sobre las minorías étnicas. De ser así, resultaría suficiente refinar los mecanismos de la hermenéutica jurídica, o simplemente, expedir nuevas normas. Sin embargo, en el discurso jurídico subyace el historicismo como determinante de los mecanismos jurídicos, por lo que es preciso comprender cómo es que este opera.

\section{Historicismo y Multiculturalismo}

El multiculturalismo jurídico puede ser comprendido como un concepto que aparece en el siglo XX luego de las transformaciones sociales vinculadas al empoderamiento de los grupos indígenas, como sostienen Bonilla (2006) y Ariza (2009); al surgimiento de conflictos étnicos y nacionalistas (IBARRA, 2005); a la emergencia de los conflictos propios de las grandes migraciones (IBARRA, 2009); así como al reconocimiento jurídico de las diferencias étnicas y nacionales encaminadas a garantizar igualdad de derechos a las minorías indistintamente de su origen étnico o nacional, o como parte de la estrategia adoptada por las élites para frenar el avance de las reivindicaciones de grupos indígenas (VAN COTT, 2000). Sin embargo, comprender de esa forma el multiculturalismo jurídico sería reducirlo a la versión de la historia política eurocéntrica contada a partir de la percepción del tiempo histórico lineal. Es necesario debatir la politica del historicismo, como la denomina Dipesh Chakrabarty (2008), sobre la cual se ha constituido la linealidad del relato que sostiene el multiculturalismo jurídico y tantos otros relatos del estilo primero en Europa luego en el resto.

El historicismo construye una idea de tiempo lineal, progresivo y ascendente; metarrelato al que Lyotard (2006) identificó como "historia universal del espíritu", y que junto a la ilustración y a la filosofía idealista, constituirían los tres grandes relatos de la modernidad. Se trata de aquella manifestación a la cual Timothy Mitchell (2000) denomina como la concepción del tiempo histórico singular, por medio de la cual se crea una historia única mediante la organización de la multiplicidad de los eventos 
globales dentro de una narrativa peculiar organizada por la progresión del principio de la razón humana, la racionalidad técnica y el poder sobre la naturaleza. Idea cercana a lo que Johannes Fabian (1983) denominó como la negación de la contemporaneidad; en tanto que Castro-Gómez (2005), en La Hybris del Punto Cero, señala como negación de la simultaneidad, expresión hallada en el Segundo Tratado sobre el Gobierno Civil, en el que Locke establece que entre las sociedades europeas contemporáneas y las americanas existe una "relación de no simultaneidad"

Como señala Chakrabarty (2008), los embates contra el historicismo son derivados de los trabajos de Foucault; sin embargo, autores como Ashis Nandy (1995) y Arif Dirlik (2000) propusieron formas agudas de este debate. Para Nandy, los historiadores intentan desnudar el pasado sobre las bases de un marco de referencia que permite ordenar los datos en términos de retorno, progreso y etapas, y así, desentrañar el proceso secular y el orden sobre el cual se basan las realidades manifiestas de tiempos pasados, presumiendo que hay un solo pasado. Para Dirlik persiste aún el colonialismo historiográfico nugatorio de la historicidad de muchos pueblos en el mundo, capturando la verdad de la historia, de la opresión y de la resistencia a ella, lo que hace urgente visibilizar otras historias mediante una referencia constante al pasado precolonial. No obstante, señala que al hacerlo se corre el riesgo de deshistorizar o reificar el pasado, ante lo cual es preciso recordar que la batalla es también por el presente y sus problemas. Dirlik señala que la batalla por la historia no es más entre el colonizador y el colonizado sino entre los mismos colonizados, entre aquellos que se olvidaron del inmediato pasado y aquellos que insisten en recordarlo.

Gayatri Chakravorty Spivak (2010) propone una crítica en contra del historicismo y la concepción del tiempo que este produce. En Crítica de la Razón Poscolonial, Spivak ofrece un argumento novedoso contra la concepción del tiempo propia de la historia como disciplina. Spivak alude a una noción de Tiempo en mayúscula como una serie de leyes reales (positivas) del movimiento, o como ella las denomina: "Ley sobre el grafo", en nombre de las cuales la vida y la historia se descalifican en beneficio de un interés dominante; leyes que no sólo se producen en occidente, sino también de aquello considerado como la cultura periférica, 
señalando así una complicidad estructural entre textos dominantes producidos en ambos lados de la frontera. En la primera parte de su obra, Spivak ofrece una lectura comparativa y "crudamente «dialéctica»", de la narración épica hindú del Gitã y de algunos textos de Hegel, entre ellos Filosofia del Derecho. Sostiene Spivak a propósito de la obra de Hegel: "El Tiempo del Derecho tiene los espacios de un jeroglífico, cuya lectura activa producirá la organización del tiempo (timing) de la historia." (p. 50) Estas líneas constituyen una crítica profunda a la manera como trabaja el derecho, particularmente, a la manera como dentro de la disciplina jurídica se construye su historia, o la historia que se ha contado de ésta en perspectiva lineal-evolutiva.

La tesis de Spivak se confirma fácilmente al revisar dos obras canónicas del derecho moderno: la Teoría pura del derecho de Hans Kelsen (2003) y el Concepto de Derecho de H.L.A. Hart (2004). En estas, aunque de diferentes maneras, se establece una clasificación entre sociedades civilizadas: aquellas que establecieron la norma fundamental como criterio socialmente aceptado de validez del ordenamiento (kelsen, 2003), o identificaron la regla de reconocimiento (Hart, 2004); en oposición a las sociedades atrasadas o primitivas (en la terminología de Hart), las cuales son incapaces de distinguir el derecho de la moral (Kelsen, 2003), carecen de un criterio uniforme y socialmente aceptado de validez (Hart, 2004) o estructuran su ordenamiento sobre la base de los mitos. Estas últimas se ubican en un tiempo que no es el de la civilización noratlántica; pueden estar en el mismo espacio, pero atrás en el tiempo según el historicismo. Así, la obra de Hart, por ejemplo, señala que existen sociedades carentes de un sistema jurídico evolucionado, lo cual sustenta en los reportes etnográficos de la antropología del siglo XIX (FITZPATRICK, 1998) ${ }^{1}$.

La manera del relato histórico presente en las obras mencionadas organiza el tiempo de los pueblos que se han sometido (voluntariamente o no) al derecho occidental, construye una diacronía en la que las etapas de la vida social se suceden unas a otras, con términos preclusivos como

${ }^{1}$ Para un debate más amplio sobre las críticas de Fitzpatrick a Hart en relación con el mito, se sugiere: Grosso y López (2011). 
si de un proceso judicial se tratara, ordenada y consecutivamente en el tiempo; narrativa en la que los hechos probados del pasado son tomados por reales, como en el historicismo, y si no pueden ser probados, sencillamente se asume que no ocurrieron.

Otro ejemplo de la manera como se relacionan el discurso historicista y el derecho, se encuentra en el análisis que hace Samera Esmeir (2007) del derecho procesal isrraelí. Ella argumenta a propósito del conflicto palestino israelí promovido desde 1948, cuando el estado Sionista invade la villa palestina de Tantura, que el derecho positivo y la historiografía guardan una profunda semejanza, en tanto ambas disciplinas separan el pasado del presente como dos momentos diferentes en el tiempo. Se trata de una ficción, pues las memorias producidas no están en el pasado o en el presente, sino son las mismas memorias las que definen el flujo del tiempo. Para Esmeir hay un relato alternativo que emerge fuera de las categorías temporales convencionales (pasado y presente) pero que es ocultado por regímenes de verdad, como la objetividad y la coherencia gobernantes de las memorias. Tales regímenes desacreditan los relatos alternativos mostrándolos como contradicciones, ausencias o incoherencias. La muerte, por ejemplo, no sería simplemente un evento más ocurrido en un determinado tiempo; la muerte genera la miseria presente, y en ese sentido, no está simplemente en el pasado entendido como un momento del tiempo. Los testimonios sobre la muerte rendidos en los procesos judiciales luego de la invasión a Palestina, son valorados por el derecho israelí con base en las exigencias de coherencia y precisión con los que también son valorados por la historiografía. El sistema jurídico de Israel descarta de plano un testimonio cuando presenta incoherencias o contradicciones. Sin embargo, argumenta Esmeir, tratándose de un hecho traumático que sigue generando efectos en el presente, la coherencia y la precisión son lujos que el narrador no se puede dar sin arriesgar en exceso su propia estabilidad emocional, pues recordar la muerte es parte de su efecto presente. Al cuestionar las reglas del proceso judicial en Israel tanto como el procedimiento historiográfico, Esmeir (2007, p. 249) concluye que: “[...] incoherencias, contradicciones y ausencias deben ser entendidas como significados de algo que aún está 
en el presente - la muerte de las relaciones humanas, la limpieza étnica de los palestinos y la destrucción de una sociedad entera."

A partir de los planteamientos de Esmeir y de Spivak, así como de los argumentos de Martha Zambrano que serán expuestos más adelante, es posible argumentar que el propósito de ordenar los eventos de la vida al estilo del proceso judicial, constituye el fundamento que legitima la narrativa del derecho; la forma como funciona el proceso judicial, busca permear otras esferas de las relaciones sociales, constituyéndose así la cultura de judicialización de la vida cotidiana.

La forma como ocurre esta judicialización de la vida cotidiana tiene lugar en nuestra cultura desde hace más de cuatro siglos, como se evidencia en lo planteado por Marta Zambrano (2000) a propósito del efecto de la escritura legal durante la colonia. Según Zambrano, entre los siglos XVI y XVIII, la mayoría de los pobladores del Nuevo Reino de Granada, incluyendo colonizados, colonizadores pobres y mujeres de toda condición, ignoraban las formas de comunicación escritural no obstante que sus vidas eran parcialmente gobernadas por ordenanzas, cédulas reales, sentencias, decretos, resoluciones y demás textos jurídicos producidos por la Corona. Estas normas escritas afectaban sensiblemente la cotidianidad, obligando a las personas a conocer la ley y a recurrir a los medios escriturales para tratar de mitigar los efectos de las decisiones legales del Reino. Para Zambrano, la mayoría de las cartas nunca llegaron a su destino, pero al igual que todas las expresiones documentales de la ley, eran celosamente guardadas por la Corona en un archivo cuidadosamente dispuesto como memoria histórica que cubría casi todos los aspectos de la vida cotidiana. De esa forma, se escribía la historia de la conformación del imperio, una historia legal y perfectamente documentada, aunque no necesariamente verdadera, o simplemente verdadera en tanto evidencia documental.

Zambrano (2000, p. 167) explica este refinado mecanismo de archivo producido en la Colonia para argumentar, apoyándose en Rappaport y Cummins, que existe una estrecha relación entre las escrituras marcadas por la impronta de la ley y otros sistemas de notación y comunicación desplegados desde esa época que a su vez determinaron 
la manera como se produjeron otras formas escriturales, incluyendo las no institucionales, y adicionalmente, cómo las “[...] prácticas históricas, sociales y políticas de alfabetización, conformaron un locus crucial de la cultura colonial porque el discurso legal gobernó un régimen de verdad".

Así como la escritura legal colonial determinó las formas de comunicación y de producción de otros textos, la lectura activa del grafo producido por el Tiempo del Derecho organiza el tiempo de la historia, y así, se produce el efecto de judicialización de la vida cotidiana. Así, la narrativa del tiempo unilineal, propia de un proceso legal, es incorporada por las personas en sus acciones cotidianas.

El tipo narrativo diacrónico del derecho constituye la dinámica interna de construcción ideológica de los fundamentos del relato a discutir, mismos que aparecen reiteradamente en la literatura sobre el multiculturalismo jurídico, según la cual este puede ser: un enunciado emergente (no hace más de un siglo) de las reivindicaciones (ya sea de un trato igualitario o uno diferencial) elevadas por grupos minoritarios con base en identidades étnicas o nacionales que los distinguen de otros grupos, o una consecuencia de la evolución en la teoría de los derechos humanos provocada fundamentalmente por unos hechos sociales ocurridos durante el siglo XX como consecuencia de esa misma emergencia.

El historicismo, que promueve aquello denominado por Walter Benjamin (2008) como tiempo homogéneo vacío, sostiene el multiculturalismo jurídico como enunciado inscrito en el positivismo científico. Al dejar de observar el tiempo como algo lineal, y aceptar la posibilidad de otras temporalidades en las que historias no contadas aún, transmodernas como señala Dussel (2004), periféricas, o simplemente otras formas persistentes, persisten como legados de los pueblos negados en su propia historicidad, podremos admitir formas alternativas de construir la identidad y la justicia. Mirar las prácticas discursivas que constituyen el multiculturalismo, es decir, observarlo en un sentido no historicista, implica tomar el multiculturalismo como un dispositivo compuesto por prácticas discursivas acerca de la identidad y la diferencia, 
presentes a través de la historia de la colonización persistente en la colonialidad del poder.

A partir del análisis expuesto, en lo que sigue se presenta un ejemplo acerca de la manera como el discurso del multiculturalismo jurídico se apoya en una narrativa historicista. Esto implicará reflexionar sobre la relación entre justicia e identidad en entornos multiculturales marcados por contextos coloniales. Con ese propósito, en la siguiente sección de este artículo ese evidencian prácticas concretas del relato historicista presente en la interpretación judicial de la Corte Constitucional colombiana. Para ello, se analizará la jurisprudencia relativa a las medidas de protección de pueblos indígenas en Colombia.

\title{
4 Retóricas del Multiculturalismo en la Jurisprudencia de la Corte Constitucional Colombiana
}

\begin{abstract}
En el constitucionalismo colombiano el multiculturalismo es un pilar de la nacionalidad y en consecuencia el Estado tiene la obligación de reconocer y proteger la diversidad étnica y cultural $\mathrm{y}$, adicionalmente, promover dicha diversidad, de lo cual depende la convivencia armónica dentro de una democracia participativa. (CORTE CONSTITUCIONAL SENTENCIA T-778 de 2005)
\end{abstract}

Como ha sido señalado en otros momentos (López, 2011), el fundamento del nacionalismo para la Corte hace tiempo que dejó de ser la homogeneidad. A lo largo de la segunda mitad del siglo XX, la diversidad cultural pasó de ser un obstáculo para la construcción de la nación a un valor que era necesario conservar. Pero ¿conservar por qué, para qué, para quiénes? Hoy es claro que la diversidad cultural, étnica, sexual, entre otras, puede también ser convertido en mercancía, objetos de consumo que impulsan rentables negocios como el turismo, la publicidad y otras grandes industrias culturales.

Razón tenía Hall (2010) al señalar que la noción monolítica de una "formación nacional", de una "economía nacional", de una entidad que podría ser representada a través de una "identidad cultural nacional", 
se encontraba bajo una presión considerable y tendía cada vez más a desaparecer bajo las formaciones contemporáneas de la globalización. Afirmación que no obstante parece hoy desvirtuarse con la intención presente en algunos países de cerrar sus fronteras y cobijarse de nuevo bajo la idea de nación, como lo evidencia el brexit, y otros intentos latentes de seguir el mismo camino, como algunos proponen en Francia y en Austria.

Para Hall (2010), el estado-nación no está desapareciendo, por el contrario, se está atrincherando de manera más fuerte para quedarse por más tiempo, en una forma diferente y paradójica, que él ha denominó como el "exclusivismo defensivo". Un ejemplo de esta tendencia la encontramos en influyentes pensadores europeos como Giovanni Sartori (2001) y su idea de sociedad plural, como una manera renovada de racismo de estado, tan atractivo para los movimientos conservadores de Europa. Posturas como la de Sartori aparecen por todas partes del mundo. Al respecto, plantea Hall (2010, p. 508) a partir de la experiencia del tatcherismo: "[...] cuando la era de los estados-nación comienza a decaer con la globalización, uno puede observar una regresión hacia una forma de identidad nacional, muy defensiva y altamente peligrosa, motivada por una forma muy agresiva de racismo".

El ideal del estado nación no desparece, aunque sus fronteras puedan deslizarse constantemente. La identidad sería apenas una de esas fronteras en constante cambio, y sus movimientos pueden ser observados en dinámicas concretas, por lo cual cabe preguntarse ¿cómo explicar la idea de identidad cultural nacional que la Corte Constitucional promueve a través de sus fallos judiciales? ¿qué busca propiciar la jurisprudencia constitucional mediante la cual se dice proteger la diversidad étnica y cultura como fundamento de la identidad nacional?

El conflicto armado en Colombia ha afectado a todos los grupos que habitan el territorio sin excepción. No obstante, es innegable que el conflicto ha incidido en la vida de algunos de mayor manera que en la de otros. Entre los más afectados se encuentran los pueblos indígenas, afrodescendientes y campesinos. Ante la grave situación de los pueblos indígenas víctimas del desplazamiento forzado y otros 
crímenes atroces cometidos en Colombia por todos los actores armados, la Corte Constitucional expidió el Auto 004 de 2009 como una medida de adicional de acuerdo a lo dispuesto en la Sentencia T-025 de 2004. La eficacia limitada de esta medida, ha generado controversia entre muchos analistas, como puede hallarse en los trabajos de García (2009) y Rodríguez (2009), pero también ha generado reacciones diversas entre los miembros de los pueblos indígenas. Sin embargo, no son estas reacciones las que me interesan en este artículo, sino la manera como el Auto 004 de 2009 ejemplifica el historicismo que caracteriza al discurso jurídico multicultural promovido por la jurisprudencia de la Corte Constitucional en aquellas ocasiones en las cuales ha tenido que ocuparse de la tensión entre identidad nacional y el derecho a la identidad cultural de los pueblos indígenas. A continuación reconstruiré de manera crítica los elementos centrales del Auto 004 para exponer esta tensión.

Según el Auto 004 los miembros de los «pueblos indígenas», y los pueblos mismos, se encuentran en estado de indefensión ante el desplazamiento y otras amenazas a los derechos fundamentales como consecuencia del conflicto armado en Colombia. La Corte argumenta que los riesgos propios del conflicto armado son resultado de la crisis estructural de abandono institucional y pobreza preexistentes, agudizada por el desplazamiento, las masacres, los asesinatos selectivos, las desapariciones, las torturas y muchas otras formas de violaciones a derechos fundamentales de los miembros que conforman los pueblos indígenas en mayor situación de riesgo.

Esa situación crítica, según la Corte, transcurre en una contradictoria situación de reconocimiento y simultáneo desconocimiento de la diferencia cultural, una contradicción entre la realidad y la representación de la realidad, determinada por la ambivalente relación existente dentro de la sociedad colombiana que se precia de su carácter multicultural, de sus riquezas étnicas y de distintos aspectos de las culturas indígenas nacionales, al mismo tiempo que se torna indiferente ante el horror y el menosprecio cultural vivido por las mismas comunidades.

Para la Corte Constitucional, las violaciones a los derechos humanos cometidas en contra de los miembros de los grupos indígenas afectados 
por el conflicto armado, ponen en riesgo -además de sus vidas y las de sus comunidades- el principio de respeto a la diversidad etnocultural. Según este principio "la aceptación de la alteridad (está) ligada a la aceptación de la multiplicidad de formas de vida y sistemas de comprensión del mundo diferentes de los de la cultura occidental. Constituyendo una proyección, en el plano jurídico, del carácter democrático, participativo y pluralista de la república colombiana." Corte Constitucional SU-510 de 1998

Pero ¿es la "cultura occidental" algo tan homogéneo? Si es así ¿podría decirse que todos los "no indígenas", "afrodescendientes" o "rom", entre otros, hacen parte de tal "cultura occidental"?

La Corte sostiene que mediante el principio de respeto a la diversidad etnocultural se garantiza la existencia de la nacionalidad, la cual en virtud de la Constitución del 91 es heterogénea, pluriétnica y multicultural. Así, la nacionalidad colombiana que garantiza nuestro ordenamiento es una nacionalidad fundada en el respeto por la diferencia, pese a lo cual, el Estado no renuncia a la idea de nación como estamento común que nos reúne en las diversas formas de ciudadanías presentes en el territorio.

¿Qué implicaciones puede tener el reconocimiento del principio de respeto a la diversidad etnocultural en la garantía de los derechos fundamentales de los pueblos indígenas? La nacionalidad debe ser interpretada en armonía con los contenidos materiales de los principios y los derechos fundamentales. Ahora, conforme a la teoría del derecho constitucional propuesta por Zagrebelsky (2003), los principios del ordenamiento jurídico conviven de manera interconectada, constituyendo una red axiológica que permite identificar aquellos principios y valores consustanciales al modelo jurídico político de Estado elegido por la sociedad. La existencia e identificación acertada del catálogo axiológico, debe promover la construcción de un orden jurídico más incluyente y justo.

Pero establecer qué hace parte del catálogo axiológico resulta una tarea compleja. Tratándose del principio del respeto a la diversidad etno cultural como fundamento de la nacionalidad colombiana, la Sentencia SU-510 de 1998 estableció la relación de conexidad entre dicho principio 
y la igualdad, al señalar que aquel principio se sostiene en el artículo 70 de la Constitución Política, según el cual, la cultura en sus diversas manifestaciones es el fundamento de la nacionalidad y es deber del Estado reconocer la igualdad y la dignidad de todas las culturas. De donde se puede afirmar que es la "igualdad", como valor, la que sustenta el principio del respeto a la diversidad etnocultural, dado que sólo es posible garantizar la diversidad "si y solo si" todas las culturas coexistentes en la nación son tratadas como iguales.

De modo que la igualdad a la que alude la Corte es entre culturas, pese a que la igualdad jurídicamente garantizada por el derecho constitucional es relevante en tanto se predica de personas como miembros de las culturas, no de las culturas en sí mismas. No obstante, la Corte Constitucional se refiere a una igualdad fáctica, igualdad como hecho entre las culturas; igualdad que carece de sustento lógico en el derecho constitucional en tanto precisamente esta disciplina se funda en la igualdad como prescripción para los sujetos, esto es, para las personas que integran los diferentes grupos humanos. Las culturas no son sujetos de derechos, sus integrantes si.

Y lo más importante: la igualdad no es más que una convención, un mecanismo de valoración de todas las diferentes identidades que pueden coexistir incluso dentro de lo que la Corte denomina una misma "cultura". Como señala Ferrajoli (2008) es necesario reconocer que el principio de igualdad es una norma, esto es, una convención que creamos para valorar las diferencias identitarias en atención a las diferencias irreductibles que nos caracterizan como seres humanos. Pero las desigualdades son hechos, y se conviene el principio de igualdad como una forma de reconocer igual valor de todas las diferencias personales, empezando por las culturales, "que hacen de cada persona un individuo diferente de todos los demás y a cada individuo una persona igual a las otras". (Ferrajoli, 2004 p. 76) Por supuesto dicha proclama opera contra la realidad, de donde se deduce que es una prescripción que busca modificar la realidad inequitativa.

De otro lado, el principio de igualdad material implica garantizar a todos los miembros de la sociedad el disfrute efectivo de los derechos fundamentales. Tal objetivo se logra de diversas maneras, incluso tratando 
de forma desigual a los que no están en la misma posición. Así también lo sostiene Gerardo Pisarello (2007), para quien el sentido de los derechos fundamentales no es otro que garantizar la igualdad material, pues su realización permite la eliminación de las diferencias odiosas introducidas por los sistemas económicos, sociales o culturales.

De manera que si el fundamento del respeto a la diversidad etnocultural es la igualdad, y esta implica tratamientos diferenciales, debe tenerse el suficiente cuidado de infligir tratamientos desiguales solo a quienes materialmente son diferentes, y por otro lado, garantizar que todos aquellos que integran la diferencia sean cubiertos por la misma medida, de lo contrario se daría paso a una nueva discriminación. Esto es precisamente lo que no ocurre en el Auto 004 de 2009. Esta decisión supone una protección de las personas a quienes les han sido vulnerados sus derechos como consecuencia del conflicto armado. La necesidad de la protección, como ya se ha dicho, es la indiferencia mostrada por una sociedad que se precia de ser multicultural y valorar "lo indígena", pero al mismo tiempo es indiferente ante la vulneración de los derechos humanos de los miembros de los pueblos indígenas, situación que amenaza la diversidad cultural.

¿Por qué la Corte Constitucional selecciona sólo a algunos grupos? Si bien es cierto que existen diversos grados de amenaza, la realidad es que todos los pueblos indígenas se encuentran en situación de vulneración de sus derechos fundamentales. Aunque mediante decisiones posteriores la misma Corte fue ampliando los alcances el Auto 004 de 2009 a pueblos indígenas inicialmente no incluidos, muchos pueblos indígenas siguen excluidos. Si la intervención de la Corte busca defender grupos humanos como portadores de una identidad colectiva como componente de la diversidad cultural, la protección no se puede dirigir únicamente a grupos concretos, sino a todos los pueblos sin excepción pues no existe una cultura más importante que otra.

Ahora bien, para garantizar de forma coherente el mencionado valor de la diversidad cultural ¿sería suficiente proteger a los pueblos indígenas más amenazados? y de otro lado ¿la diversidad cultural de la nación existe únicamente por la persistencia de algunos grupos indígenas 
u originarios? Por último: ¿si solo se protege a algunos grupos no se rompería la igualdad material como sustento del principio de respeto a la diversidad etno cultural? Se trata de una práctica propia del discursos historicista a través de la cual se enuncia con autoridad lo "verdadero": grupos indígenas que deben ser protegidos porque están en riesgo, o: no todos los grupos corren el mismo riesgo de vulneración.

Un desarrollo de esta idea puede verse con claridad en otro elemento que resulta polémico en el Auto 004: la afirmación de la Corte constitucional según la cual los pueblos indígenas se encuentran en estado de indefensión. Según la Corte Constitucional, el estado de indefensión se "[...] manifiesta cuando la persona ofendida se encuentra inerme o desamparada, es decir sin medios físicos o jurídicos de defensa o con medios y elementos insuficientes para resistir o repeler la vulneración o amenaza de su derecho fundamental" (Corte Constitucional Sentencia T-1236 de 2000).

Para la Corte Constitucional, los integrantes de los pueblos indígenas son personas incapaces de procurarse mecanismos de protección autónomos para repeler las amenazas a sus derechos fundamentales al encontrarse inermes o desamparados ante tales circunstancias. Pero ¿por qué estos grupos, a diferencia de otros, se encuentra en especial estado de desprotección, inermes y desamparados? ¿qué es lo que hace tan particulares a los pueblos indígenas? ¿es acaso el hecho de pertenecer a un pueblo indígena una condición de incapacidad y carencia de medios físicos o jurídicos de defensa para oponerse a las consecuencias del conflicto? ¿es esta una forma matizada de desconocer la legitimidad de otros medios de defensa empleada por los pueblos como las "guardias indígenas"?

A los pueblos indígenas se les imputa un estado de indefensión en la jurisprudencia, algo no muy distinto a lo que hizo el poder ejecutivo en julio del 2012 cuando, omitiendo el derecho a la autonomía territorial del pueblo Nasa en Toribio (Cauca), pretendía mantener en contra de la voluntad del pueblo el batallón de alta montaña n. 8 en el cerro Las Torres del municipio de Toribio. El argumento del poder ejecutivo era el mismo de la Corte: los indígenas no se pueden proteger por sí mismos 
de la guerrilla, por eso se necesita la presencia del Estado a través del Ejercito Nacional dentro de su territorio para defenderlos. A la estrategia retórica del gobierno amparado en el argumento jurídico del "estado de indefensión" de los indígenas, pese a que conforme al derecho internacional, el batallón que pretendía el Gobierno no podía ubicarse en ese lugar².

La Corte Constitucional, como también lo hace el poder ejecutivo, no duda en afirmar la condición del paternalismo protector. Se trata de un vector discursivo presente en las políticas coloniales, desde la discusión entre Gines de Sepúlveda y Bartolomé de las Casas sobre la naturaleza de los salvajes, hasta los móviles (altruistas pero discutibles) de los indigenistas colombianos del siglo XX. Vector que no desparece con la constitución de la república, por el contrario, se reedita en formas diversas de menosprecio cultural y arrogancia, que reaparece con distinto ropaje en el estado multicultural; así, el enunciado puede cambiar, pero no el régimen discursivo que lo sostiene.

La misma Corte Constitucional considera que la indiferencia ante el horror vivido por las comunidades indígenas es una forma de menosprecio cultural, indiferencia que ahora se nos revela gracias a la contradicción entre la realidad de las comunidades (violaciones por causa del conflicto) y la representación de dicha realidad (la valoración de la multiculturalidad y de la riqueza étnica de la nación). Pero la Corte Constitucional no cuestiona la manera en que la representación -que es ubicada por la Corte en el plano de la ficción como antagonista de la "realidad"- no sólo no es algo irreal, sino que es producto de prácticas discursivas construidas, reforzadas y avaladas por múltiples actores, entre ellas la misma Corte Constitucional. El concepto de "representación" que la Corte emplea se

\footnotetext{
${ }^{2}$ La Declaración de las Naciones Unidas sobre los Derechos de los Pueblos Indígenas establece en su artículo 30: 1. No se desarrollarán actividades militares en las tierras o territorios de los pueblos indígenas, a menos que lo justifique una razón de interés público pertinente o que se haya acordado libremente con los pueblos indígenas interesados, o que éstos lo hayan solicitado. 2. Los Estados celebrarán consultas eficaces con los pueblos indígenas interesados, por los procedimientos apropiados y en particular por medio de sus instituciones representativas, antes de utilizar sus tierras o territorios para actividades militares.
} 
reduce a una ficción que diverge de la realidad supuesta de la identidad indígena, sin embargo, la representación, como señalan Gómez y Gnecco (2008, p. 11) es "[...] un espacio retórico en el cual alguien impersona a otro". La representación implica la existencia de otro ubicado en un lugar diferente en lugar del cual aparece aquello que lo suplanta, es decir, una representación intencionalmente promovida por el representador.

La Corte Constitucional, aunque toma la representación como una simple ficción, ella misma representa, en la medida que construye una identidad mediante la cual define la condición del sujeto indígena.

Las representaciones legales en particular, crean sujetos e identidades cuya caracterización depende de marcos de interpretación que trascienden los límites de su propio despliegue y que determinan, en buena medida, el curso de la vida social (sobre todo la relación del Estado con los sujetos que dice representar). La juridicidad del otro no es otra cosa que su reconocimiento (negativo o positivo) en el discurso del Estado de manera que su (in) existencia legal es, simultáneamente, el signo de su (in)visibilidad nacional. (GÓMEZ; GNECCO, 2008, p. 12)

La Corte no se cuestiona por la manera en que, mediante la retórica exotizante y esencialista de su propia jurisprudencia, de las prácticas comerciales, de los discursos etnoambientalistas, del ecoturismo, entre otros, los pueblos indígenas se han convertido, una vez más, en un fetiche, objeto de patrimonialización, reminiscencia de un pasado diverso que debe ser conservado y protegido de la voracidad del desarrollo y la modernidad, el objeto de una nostalgia conspicua marcada por la culpa colonial.

La Corte ha construido una representación de la diferencia como fundamento de la nacionalidad, como bien jurídico constitutivo de la unidad, de la diversidad como patrimonio de la humanidad. Una representación de la "cultura indígena" como un bien de la nación que debe ser rescatado, sujetos indígenas a quienes se les debe proteger su "identidad" indígena, incluso de ellos mismos. 
Por último, es cuestionable la manera como la Corte Constitucional es incapaz de advertir otros factores de violencia cultural distintos a los derivados del conflicto armado. Por ejemplo, la Corte no incluyó la represión religiosa como uno de los componentes principales de la confrontación que se cierne sobre las comunidades indígenas. Este es otro ejemplo de la manera como procede el historicismo: se crean secciones, etapas temporales que resuelven la continuidad entre un pasado colonial y la constitución de la república. Uno de los elementos estructurantes de la violencia en contra de las comunidades indígenas en una perspectiva histórica que trasciende el periodo de violencia armada más reciente, se halla en la responsabilidad atribuible a las prácticas religiosas de penetración cultural que históricamente han tenido presencia en el territorio de los pueblos indígenas.

Al respecto, existe evidencia de los atropellos cometidos por la iglesia católica en departamentos como el Putumayo según lo expuesto por Víctor Bonilla (2006), en la zona andina como expone Mercedes López (2001), o en el Chocó como muestra Werner (2000), y en tantos otros lugares del país, sin que ningún organismo del Estado haya exigido a la iglesia católica reparación alguna por los hechos cometidos contra los pueblos indígenas en Colombia.

La retórica de la Corte Constitucional debería ser impugnada cuando en casos como los de la Sentencia SU-510 de 1998 se avala la prohibición dentro del territorio arhuaco de la iglesia Pentecostal en defensa de la religión tradicional de los arhuacos, pero en la controversia entre la OXY y el pueblo Uwa la misma Corte permite la explotación del hidrocarburo a pesar de la objeción religiosa presentada por los Uwa a la actividad de la petrolera. ¿El desconocimiento de los valores religiosos como objeciones válidas a la explotación minera que ha provocado que los miembros de la Comunidad Uwa amenacen con su autodestrucción no es acaso un factor de violencia cultural que lleva a la muerte física y social de los pueblos? 


\section{Conclusiones}

En la medida que el derecho se constituye sobre la política del historicismo se perpetua a través del derecho un régimen que organiza el tiempo de la vida mediante fases preclusivas, que se suceden de forma ordenada una a otra. No obstante, la vida cotidiana se escapa de esta forma de organización del tiempo, buscando fluir por cauces no lineales, por el contrario, sinuosos.

En este artículo se expuso la manera como el historicismo ha constituido el discurso del derecho: aquello que le otorga su legitimidad en el tiempo, su condición de producto de la racionalidad occidental está basado en una tradición inventada por los historiadores en Europa desde el siglo XVII. La concepción del tiempo que el historicismo presupone, se preserva en muchas prácticas jurídicas, y a su vez, se cuestiona en aquellas que confrontan visiones de mundo diferentes. La jurisprudencia constitucional colombiana, incluso aquella que busca garantizar los derechos fundamentales de los miembros de los pueblos indígenas, está igualmente basada en la concepción del tiempo construida por el historicismo como elemento que estructura el derecho moderno; de allí que la tensión entre la búsqueda de una nación incluyente pero ordenada conforme a los criterios de la sociedad mayoritaria que se precia de civilizada y racional, y las luchas por la identidad de los pueblos indígenas, resulte inevitable y quizás insoluble.

Sería necesario que el derecho occidental, tanto el derecho de los estados (o el que imponen las multinacionales a los estados) como el derecho internacional, esté dispuesto a aceptar otras nociones de tiempo no ordenado cronológicamente, no lineal; en tanto algo así no tenga lugar, persistirá el sistema de derecho que busca reducir la diferencia, que por naturaleza es irreductible. 


\section{Referencia}

AGUILERA, Mario. La legislación y el derecho en Colombia. Sinopsis histórica desde la conquista hasta el presente. In: AGUILERA, Mario. Historia Extensa de Colombia. Bogotá, Ediciones Lerner, 1965. v. XIV. ARIZA, Libardo. Derecho, saber e identidad indígena. Bogotá: Siglo del Hombre Editores, Universidad de los Andes, Pontificia Universidad Javeriana, 2009.

BONILLA, Daniel. La Constitución multicultural. Bogotá: Siglo del Hombre; Instituto Pensar, 2006.

BONILLA, Víctor. Siervos de Dios y amos de indios: El estado y la misión capuchina en el Putumayo. Popayán: Editorial Universidad del Cauca, 2006.

BERNAL, Martín. Atenea negra: Las raíces afroasiáticas de la civilización clásica - Volumen I La invención de la antigua Grecia, 17851985. Barcelona: Editorial Crítica, 1993.

CASTRO-GÓMEZ, Santiago. La Hybris del Punto Cero: Ciencia, raza e ilustración en la Nueva Granada (1750-1816). Bogotá, Instituto Pensar, 2005.

CHAKRABARTY, Dipesh. Al margen de Europa: Pensamiento poscolonial y diferencia histórica. Barcelona. Tusquets Editores, 2008.

DIRLIK, Arif. Posmodernity's histories: the past as legacy and project. Lanham, MD: Rowman \& Littlefield Publishers Inc., 2000.

DUSSEL, Enrique. Sistema mundo y transmodernidad. In: DUBE, Saurabh; BANERJEE, Ishita; MIGNOLO, Walter (ed.). Modernidades coloniales. México: El Colegio de México, 2004. p. 201-226.

DUSSEL, Enrique. Política de la Liberación: Historia mundial y crítica. Madrid: Editorial Trotta, 2007.

DE GAUDUSSOND, J. D. B. La influencia del derecho francés en las instituciones jurídicas del Tercer Mundo. Iusta, [S.l.], n. 30, p. 141-151, 2009. 
ESMEIR, Samera. Memories of Conquest: Witnessing Death in Tantura. In: SA'DI AHMAD, H.; ABU-LUGHOD, Lila Nakba: Palestine, 1948, and the Claims of Memory. New York: Columbia University Press, 2007. p. 229-252. Disponible: doi:10.7312/sadi13578.16. Acceso en: May 11, 2020 .

FABIAN, Johannes. Time and the Other: How Anthropology Makes Its Object. New York: Columbia University Press, 1983.

FERRAJOLI, Luigi. Derechos y garantías. La ley del más débil. Madrid: Trotta, 2004.

FERRAJOLI, Luigi. Estado social y estado de derecho. In: ABRAMOVICH, M. J.; AÑóN Y CH, Courtis (ed.). Derechos Sociales Instrucciones de uso. México: Doctrina Jurídica Contemporánea, 2008. p. 11-21.

GARCÍA, Mauricio. Normas de papel. Bogotá: Siglo del Hombre, 2009. GARCÍA, Mauricio et al. Teoría Constitucional. Bogotá: Universidad Nacional de Colombia, 2013.

GÓMEZ, Herinaldy; GNECCO, Cristóbal. El teatro de la representación: discursos legales e indígenas. In: GÓMEZ, Herinaldy; GNECCO, Cristóbal (ed.). Representaciones legales de la alteridad indígena. Popayán: Editorial Universidad del Cauca, 2008.

GROSSO, José; LÓPEZ, Oscar. El mito en la retórica del derecho y la antropología. Confinamiento y posibilidades subversivas de un liberto condenado. Revista Seqüência, Florianópol|is, n. 63, p. 77-99, 2011.

FITZPATRICK, Peter. La mitología del derecho moderno. México: Siglo XXi editores, 1998.

FOUCAULT, Michel. Defender la sociedad. Buenos Aires: Fondo de Cultura Económica, 2000.

GÓMEZ, Herinaldy; GNECCO, Cristóbal. El teatro de la representación: discursos legales e indígenas. In: GÓMEZ, Herinaldy; GNECCO, Cristóbal (ed.). Representaciones legales de la alteridad indígena. Popayán: Editorial Universidad del Cauca, 2008. 
HALL, Stuart. Sin garantías: Trayectorias y problemáticas en estudios culturales. Popayán: Instituto Pensar universidad Javeriana; Instituto de Estudios Peruanos; Universidad Andina Simón Bolívar Sede Ecuador; Envión Editores, 2010.

HART, Herbert. El concepto de derecho. Buenos Aires: Abeledo-Perrot, 2004.

IBARRA PALAFOX, Francisco. La libertad de las minorías etnoculturales. In: IBARRA PALAFOX, Francisco. Tercer Concurso de Ensayo "Caminos de la Libertad" Memorias. México: Fundación Azteca; Grupo Salinas, 2009. p. 66-101.

IBARRA PALAFOX, Francisco. La evolución del debate multicultural y su estado actual en la teoría liberal. In: CÁCERES, Flores and Saldaña (ed.). Problemas contemporáneos de la filosofía del derecho. México: Universidad Nacional Autónoma de México, 2005.

KELSEN, Hans. Teoría pura del derecho. Argentina: Editorial Porrúa, 2003.

LÓPEZ, Mercedes. Tiempos para rezar y tiempos para trabajar: la cristianización de las comunidades muíscas coloniales durante el siglo XIV. Bogotá: Instituto Colombiano de Antropología e Historia, 2001.

LÓPEZ, Oscar. Los cantos de sirena del multiculturalismo jurídico político. La identidad cultural en la jurisprudencia de la corte constitucional. Revista Tabula Rasa, Bogotá: Unicolmayor, n. 14, 2011. LYOTARD, Jean-François. La condición posmoderna. Madrid. Cátedra, 2006.

MALAGÓN, Miguel; GAITÁN, Julio. Colonialismo cultural francés y la creación del Consejo de Estado en el derecho administrativo colombiano. Universitas Javeriana, Bogotá, n. 115, p. 161-178, 2008.

MANTILLA, Fabricio. La influencia del Code Civil y la doctrina francesa en el derecho de las obligaciones colombiano. Cuadernos de Análisis Jurídicos, Colección Derecho Privado II, Santiago de Chile, Ediciones Universidad Diego Portales, 2005. 
MITCHELL, Timothy. The stage of modernity. Questions of Modernity Minneapolis, University of Minnesota Press, 2000.

MONATERI, Piere Giuseppe. Gayo, El Negro: una búsqueda de los orígenes multiculturales de la tradición jurídica occidental. In: MONATERI, P. G.; SAMUEL, G. La invención del derecho privado. Bogotá: Universidad de los Andes; Facultad de Derecho, Pontificia Universidad Javeriana; Instituto Pensar, Siglo del Hombre Editores, 2006. p. 95-216.

NANDY, Ashis. History's Forgotten Doubles. History and Theory, World Historians and Their Critics, v. 34, n. 2, Theme Issue 34, 1995.

NARANJO, Vladimiro. Derecho Constitucional e Instituciones Políticas. Bogotá: Temis, 2010.

ORTIZ, Sergio. Franceses en la independencia de Colombia: Academia Colombiana de Historia. Bogotá: Editorial Kelly, 1960. v. XIX.

PISARELLO, Gerardo. Los derechos sociales y sus garantías: elementos para una reconstrucción. Madrid: Trotta, 2007.

RODRÍGUEZ, César. Mas allá del desplazamiento: políticas, derechos y superación del desplazamiento forzado en Colombia. Bogotá: Uniandes, 2009.

SPIVAK, Gayatri Chakravorty. Crítica de la razón poscolonial: hacia una historia del presente evanescente. Madrid. Akal Editores, 2010.

SARTORI, Giovanni. La sociedad multiétnica: pluralismo, multiculturalismo y extranjeros. Madrid: Taurus, 2001.

TROUILLOT, Michel-Rolph. Transformaciones globales: la antropología y el mundo moderno. Popayán: Universidad del Cauca; CESO Uniandes, 2011.

VAN COTT, Donna Lee. Latin America: constitutional reform and ethnic right. Parliamentary Affairs, [S.l.], v. 53, 2000. 
WERNER, Erik. Ni aniquilados, ni vencidos: los Embera y la gente negra del Atrato bajo el dominio español. Bogotá: Siglo XVIII; ICANH, 2000 .

ZAGREBELSKY, Gustavo. El derecho dúctil: ley, derechos, justicia. Madrid: Editorial Trotta, 2003.

ZAMBRANO, Marta. La impronta de la ley: escritura y poder en la cultura colonial. In: GNECCO, Cristóbal; ZAMBRANO, Marta. Memorias hegemónicas, memorias disidentes: el pasado como política de la historia. Bogotá: ICANH; Universidad del Cauca, 2000.

Oscar Andrés López Cortés é docente pesquisador na Universidade Livre, Colombia. Ph.D. em antropologia, mestre em Direito. Advogado.

E-mail: oscara.lopezc@unilibre.edu.co

Endereco profissional: Universidad Libre, Centro de Investigaciones, Calle $8 \mathrm{n}$. 5-80, Bogotá, Colombia.

ORCID: https://orcid.org/0000-0002-7589-7233

Tulio Enrique Rojas Curieux é professor na Universidade de Cauca, Colombia. Doutorado em linguística teórica. Mestrado em etnolinguística. Graduado em Ciências Sociais.

E-mail: trojas@unicauca.edu.co

Endereco profissional: Universidad del Cauca, Sede el Carmen, Popayán, Colombia.

ORCID: https://orcid.org/0000-0002-2724-6022 